\title{
Future Directions of Immunoglobulin Therapy: Foreword
}

\author{
MARK BALLOW, ${ }^{1}$ ARNOLD I. LEVINSON, ${ }^{2}$ ERWIN GELFAND, ${ }^{3}$ and STANLEY A. SCHWARTZ ${ }^{4}$
}

This is our second symposium on the future directions of immunoglobulin therapy. While the first symposium explored the mechanisms of action of intravenous immune globulin (IVIG) and its use in various clinical disorders, this symposium has taken a new direction in reviewing the potential therapeutic role of monoclonal antibodies in the treatment of malignancy and autoimmune diseases.

It has been 16 years since Köhler and Milstein (1) successfully immortalized antibody-producing cells by fusing them with mouse myeloma cells. The ability to generate hybridoma cell lines producing a specific antibody has provided the tools which have had far-reaching implications in many areas of basic and clinical medicine. Dr. Matthew Scharff reviewed the fascinating history of monoclonal antibodies and the current state of hybridoma technology. For years scientists have been looking for "the magic bullet" for the treatment of malignant disorders. The concept of a specific immunotoxin, an extremely potent poison conjugated to a monoclonal antibody, has initiated a new era in cancer chemotherapy. Recent advances in monoclonal antibody methodologies, recombinant DNA, and gene transfer technologies have enabled scientists to genetically engineer antibody molecules with highly potent toxins. Drs. Ellen

\footnotetext{
${ }^{1}$ Conference Chairman and Guest Editor, Chief, Division of Allergy/Clinical Immunology, Department of Pediatrics, The Children's Hospital of Buffalo, Professor of Pediatrics, State University of New York at Buffalo, Buffalo, New York 14214. ${ }^{2}$ Moderator and Associate Editor, Associate Professor of Medicine and Neurology, Allergy and Immunology Section, The University of Pennsylvania School of Medicine, Philadelphia, Pennsylvania 19104.

${ }^{3}$ Moderator and Associate Editor, Chairman, Department of Pediatrics, National Jewish Center for Immunology and Respiratory Medicine, Professor of Pediatrics, The University of Colorado, Denver, Colorado 80206.

${ }^{4}$ Moderator and Associate Editor, Director, Clinical Immunology Section, Professor of Pediatrics, Epidemiology and Microbiology/Immunology, The University of Michigan, Ann Arbor, Michigan 48109.
}

Vitetta and Thomas Waldmann reviewed their investigations and clinical experience with this exciting, novel approach in creating a whole new class of immunotoxins for use in cancer chemotherapy. Dr. Larry Steinman presented his work on the use of monoclonal antibodies as new tools in better understanding the immunobiology of autoimmune neurologic diseases and as potential therapeutic agents.

Despite marked improvement in the survival rate of preterm infants in recent years, infection remains a major problem because of the difficulty in making a rapid and accurate diagnosis and the fact that the neonate is an immunocompromised host. It was not difficult to extrapolate the experience of using IVIG as replacement therapy in patients with primary immune deficiencies to other types of acquired or secondary immunoglobulin deficiencies. The hypogammaglobulinemia of prematurity can be most impressive in very low birth weight premature infants (2). This group of patients appears to be one that might benefit from immunoglobulin therapy. Thus it was very timely for Drs. Gerald Fischer and Carol Baker to present their experiences with IVIG therapy for neonatal sepsis in the premature infant.

In 1981, Dr. Richard Stiehm's group from the University of California at Los Angeles presented their findings on the oral administration of IVIG in premature infants as a specific modality in the prevention or treatment of enteric infections (3). This work was shortly followed by the observations of Dr. Barnes and co-workers from Australia on the use of human immune serum globulin by the oral route in the treatment of low birth weight infants with rotavirus-associated diarrhea (4). Drs. Warren Strober and Randall Goldblum reviewed the cellular and humoral aspects of mucosal gut immunity, respectively. Drs. Martha Eibl, Robert Yolken, and Peter Tutschka each presented their 
work on the potential therapeutic applications of orally administered immune serum globulin, either as specific therapy of enteric pathogens or as prophylactic regimens in patients undergoing bone marrow transplantation.

As can be seen from the foregoing outline, this symposium takes that first step in moving forward with the concept of immunoglobulin therapy in exploring new potential clinical applications, new potential routes of administration, and, more importantly, the potential applications of monoclonal antibodies and genetically engineered monoclonal antibodies in the treatment of a variety of clinical disorders.

\section{REFERENCES}

1. Köhler G, Milstein C: Continuous cultures of fused cells secreting antibody of predefined specificity. Nature 256:495-497, 1974

2. Ballow M, Cates L, Rowe JC, Goetz C, Desbonnet C: Development of the immune system in very low birth weight (less than $1500 \mathrm{~g}$ ) premature infants: Concentrations of plasma immunoglobulins and patterns of infections. Pediat Res 20:899-904, 1986

3. Blum PM, Phelps DL, Ank BJ, Krantman HJ, Stiehm ER: Survival of oral human immune serum globulin in the gastrointestinal tract of low birth weight infants. Pediat Res $15: 1256-1260,1981$

4. Barnes GL, Hewson PH, McLellan JA, Doyle LW, Knoches AML, et al.: A randomised trial of oral gammaglobulin in low-birth-weight infants infected with rotavirus. Lancet 1:1371-1373, 1982 